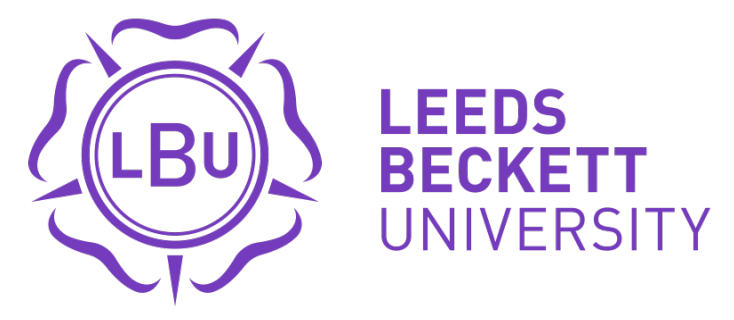

Citation:

Stansfield, J and Cavill, N and Marshall, L and Robson, C and Rutter, H (2021) Using complex systems mapping to build a strategic public health response to mental health in England. Journal of Public Mental Health, 20 (4). pp. 286-297. ISSN 1746-5729 DOI: https://doi.org/10.1108/JPMH-102020-0140

Link to Leeds Beckett Repository record:

https://eprints.leedsbeckett.ac.uk/id/eprint/8307/

Document Version:

Article (Published Version)

Creative Commons: Attribution 4.0

The aim of the Leeds Beckett Repository is to provide open access to our research, as required by funder policies and permitted by publishers and copyright law.

The Leeds Beckett repository holds a wide range of publications, each of which has been checked for copyright and the relevant embargo period has been applied by the Research Services team.

We operate on a standard take-down policy. If you are the author or publisher of an output and you would like it removed from the repository, please contact us and we will investigate on a case-by-case basis.

Each thesis in the repository has been cleared where necessary by the author for third party copyright. If you would like a thesis to be removed from the repository or believe there is an issue with copyright, please contact us on openaccess@leedsbeckett.ac.uk and we will investigate on a case-by-case basis. 


\title{
Using complex systems mapping to build a strategic public health response to mental health in England
}

\author{
Jude Stansfield, Nick Cavill, Louise Marshall, Claire Robson and Harry Rutter
}

\begin{abstract}
Purpose - This paper aims to use systems mapping as a tool to develop an organisation-wide approach to public mental health to inform strategic direction within a national public health agency.

Design/methodology/approach - Two workshops were facilitated with internal staff from a wide range of public health policy teams working in small groups to produce paper-based maps. These were collated and refined by the project team and digitised.

Findings - The approach engaged a range of teams in forming a shared understanding and producing a complex system map of the influences on population mental health and well-being, where current policy initiatives were addressing them and what the gaps and priorities were. Participants valued the approach which led to further study and organisational commitment to the whole system working as part of national public mental health strategy.

Research limitations/implications - The approach was limited to internal stakeholders and wider engagement with other sectors and community members would help further the application of complex system approaches to public mental health.

Originality/value - It was a valuable process for developing a whole-organisation approach and stimulating thinking and practice in complex system approaches. The paper provides a practical example of how to apply systems mapping and its benefits for organising public mental health practice.
\end{abstract}

Keywords Complexity, Systems thinking, Mapping, Strategy

Paper type Research paper

\section{Introduction}

Poor mental health influences many health and social outcomes and contributes significantly to population morbidity and mortality (Vigo et al., 2016). It is influenced by multiple socioeconomic and environmental factors interacting with psychological and biological processes (Patel, et al., 2018). Efforts to improve public mental health would benefit from an approach that acknowledges the complexity of these systems and aims to influence these structural drivers (Wolpert, 2018).

The 2008 Foresight report on mental capital and well-being provided an important contribution to mapping and linking the complex influences on mental health across the life course, and the range of interventions to address them across government departments (Foresight Mental Capital and Well-being Project, 2008). Whilst integrated approaches to mental and physical health have been a national policy priority in England (Department of Health and Social Care, 2011; Cabinet Office and DHSC, 2019) there has only been very limited application of complex system approaches to improving population mental health outcomes (Langellier et al., 2019). This contrasts with the impact of the 2007 Foresight report on obesity (Foresight Obesity project, 2007).
Jude Stansfield is based at Health Improvement Directorate, Public Health England, London, UK and School of Health and Community Studies, Leeds Beckett University, Leeds, UK. Nick Cavill is based at Cavill Associates Ltd, Bristol, UK and School for Policy

Studies, Centre for Exercise, Nutrition and Health Sciences, University of Bristol, Bristol, UK. Louise Marshall is based at The Health Foundation, London, UK. Claire Robson is based at Health Improvement Directorate, Public Health England, London, UK. Harry Rutter is based at the Department of Social and Policy Sciences, University of Bath, Bath, UK.

Received 30 October 2020 Revised 29 January 2021 25 February 2021

Accepted 9 March 2021

(C) Jude Stansfield, Nick Cavill, Louise Marshall, Claire Robson and Harry Rutter.Published by Emerald Publishing Limited. This article is published under the Creative Commons Attribution (CC BY 4.0) licence. Anyone may reproduce, distribute, translate and create derivative works of this article (for both commercial \& non-commercial purposes), subject to full attribution to the original publication and authors. The full terms of this licence may be seen at http:// creativecommons.org/licences/ by/4.0/legalcode

The Health Foundation. 
Equitable, sustained improvements in population mental health, along with many other contemporary public health challenges, will not be achieved through simple, linear causal models and siloed interventions, but through complex systems approaches (Rutter et al., 2017; McManus, 2017). Public Health England (PHE) (the national public health agency) has applied such approaches within whole system work to tackle obesity (Public Health England, 2019a) and health inequalities (Stansfield et al., 2020). PHE research into universal public health approaches has identified the need to "further investigate the benefits of using complex systems mapping to facilitate a whole systems approach to children and young people's mental health to understand more about the complex interplay between factors and the benefits of adopting a whole systems approach" (Public Health England, 2019d).

The above PHE research has informed the project described in this paper, which outlines an approach to engage multiple public health policy areas across PHE to contribute to the development of a whole-organisation and whole-system approach to public mental health. The premise for this work is a recognition of the cross-cutting nature of mental health within public health policy and practice and the contribution that a range of policy teams make to improving overall population mental health outcomes.

The approach used and built on a mapping methodology that had been applied by authors in the context of understanding complex systems influences on children and young people's mental health (The Health Foundation, 2018). This previous work had brought a diverse range of stakeholders together to map influencing factors at a systems level and to identify relationships between factors, exploring connections to evidence, outcomes and practice. The process provided a visual tool for elucidating potential imbalance of investment and prioritisation of efforts to address key drivers across the system, as illustrated in the feedback from one participant as follows:

As humans, we want to have a linear way of dealing with a problem, but actually this issue is so complex that it is anything but linear. The mapping process helps us to understand the complexity and see the problem in a different way. (It) "helped us to think about how helpful or unhelpful the current system of delivering support (.) is for young people with mental health issues" (The Health Foundation, 2018).

PHE identified the potential for systems mapping to be further used in the development of an allage public mental health strategy - providing the basis for creating a shared strategic vision and a coordinated organisational approach to public mental health. This paper describes the first part of that strategic approach by exploring the use of complex systems mapping.

\section{Systems thinking and mapping}

Systems thinking has been described simply as a way of seeing how things are connected to each other within some notion of a whole entity (Peters, 2014). Applied to public health, it helps "conceptualise poor health and health inequalities as outcomes of a multitude of interdependent elements within a connected whole" (Rutter et al., 2017). Systems mapping is a method of systems thinking appropriate for public health, by engaging stakeholders in conceptualising complex public health challenges and building consensus through simplified or "soft" mapping approaches (Carey et al., 2015; Cavill, et al., 2020). Group model building produces a visual depiction of how different parts of a system relate to one another (Allender et al., 2015), to illustrate how they interact and increase understanding of processes, causal mechanisms, intervention impacts, priorities and measurement indicators (Rutter et al., 2019).

\section{Purpose}

The aim was to use systems mapping as a tool to help develop an organisation-wide complex systems approach and strategy for public mental health. 
The following objectives were to:

- Engage different teams from across the organisation to work together to develop a shared understanding of the causes and determinants of mental health and well-being;

- Map potential influences on population mental health and identify where current policy initiatives address these and what the gaps and priorities are;

- Build knowledge and skills in complex system thinking and practice and organisational capacity to apply this approach to future working;

\section{Approach}

The project team (the authors) invited managers in 20 different public health programme areas to identify senior staff who could represent their programme's contribution to mental health outcomes and who would be able to champion complex systems approaches and apply it to their own programme of work. They were invited to participate in two workshops four weeks apart. Due to the large size of the organisation and the focus on capacity building attendance was kept internal.

The workshops provided an introduction to complex systems theory and practice (Rutter et al., 2017; Rutter et al., 2019; Cavill et al., 2020). The process of producing the maps was iterative across four steps to build consensus through discussion and feedback, drawing on system dynamics and group model building (Allender et al., 2015; Hovmand, 2014) as follows:

Step 1: The participants attended a workshop which included an introduction to complex systems mapping and small group work, facilitated and recorded by the project team, to discuss and produce maps of the influences on population mental health and well-being and how these connect to each other, across different systems (Box 1).

\section{Box 1. Complex systems mapping Workshop 1}

Resources: A2 paper and pens. Small groups and facilitators.

Exercise 1: Discuss and write down the factors (determinants, correlates) that are associated with mental health outcomes (positive, negative) as follows:

- Think initially about your work and its contribution to public mental health.

- Then think more broadly about the full range of influences on mental health.

Exercise 2:

- Arrange the factors into any groups that make sense e.g. how they are linked (write headings on the pages if it helps).

- What are the connections between each factor? (draw arrows showing relations).

Exercise 3:

- Each group sharing and discussing maps to the whole group. Questions, comments and reflection.

Step 2: The maps from the workshop were digitised using Kumu mapping software [1]. Kumu was chosen as it is a free and easy-to-use programme. The factors and domains within the maps were reviewed, duplicate and common themes were merged or modified and a single map was produced. The project team discussed and adjusted the factor and 
domain names and the direction of connections between them, to best reflect the discussions of participants from each of the groups they had worked with.

Step 3: At a second workshop the participants reviewed the digital versions of their original maps, along with the merged map, which was further refined following group discussion. The group then used the final version of the merged map to identify the ways in which PHE might be able to influence the system, where current priorities lie and where there are gaps (Box 2).

\section{Box 2. Complex systems mapping Workshop 2}

Resources: A2 copies of all maps. Small groups and facilitator.

Exercise 1: Introduction to the draft single map:

- Explore what's missing?

- Where can additional connections be made?

Exercise 2: Using the single draft map, identify and annotate:

- Where is PHE operating currently?

- What are we doing well? (good enough).

Exercise 3: Discuss and annotate the map to identify:

- Where are the priorities for future action?

- Where are the gaps?

- Where might we achieve more of a "system effect"?

Whole group reflection on next steps and thoughts on what needs to happen for us to take more of a whole systems approach to how we work together on public mental health.

All participants provided anonymous feedback on flipcharts at the end of both workshops on the positive aspects of the process and what would improve it.

Step 4: The project team had two further sessions to review and adjust the maps as in Step 2 and consider consistency with literature evidence for the pathways of influence identified. They amended the map so that it only depicted causal connections between elements.

\section{Findings}

A total of 40 members of PHE staff participated in the workshops covering 15 different public health programme areas (workplace health, obesity, health inequalities, health and justice, older people, cardiovascular disease, learning disabilities, epidemiology and intelligence, marketing, healthy communities, nursing and midwifery, children, young people and families, public mental health, healthy place) operating across national and regional teams. The findings are grouped into four areas: understanding the influences on mental health, identifying action on the influences, participant engagement and application and impact.

\section{Understanding the influences on mental health}

Steps 1-2: The group was divided into four smaller work groups, across which there was high consistency on what influences mental health and well-being and the domains that these fall into. A wide range of influences was combined into 53 factors across five domains 
of individual/identity, physical health/behaviour, environment, socio-economic, social/ community (Table 1). Individual identity includes psychological resources such as sense of purpose, control and resilience alongside personal characteristics of ethnicity and gender identity. Physical health/behaviour includes access to services, health status and conditions such as pain and addiction and health behaviours.

Steps 3-4: A composite map was produced of the influences on population mental health and well-being and the multiple connections between 46 factors across the five domains (Figure 1).

\section{Identifying action on the influences}

Participants were able to identify where programmes of work addressed many, but not all, of the factors in the map. The domain with most PHE actions was physical health and there was the least attention focussed on the individual identity domain.

In identifying where further focussed activity was felt to be needed, participants debated the organisation's areas of direct responsibility and where its role is in influencing and working with others on whole-system issues (e.g. homelessness, welfare support, social cohesion, ethnicity, perinatal health, working conditions, stigma, discrimination, addiction and wider determinants).

Participants felt it was important to understand the organisation's unique contributions as a system partner and where it is most likely to have a population level effect. They identified common approaches for further action (influencing legislation and mental health in all policy, knowledge mobilisation of research evidence including return on investment, data and evaluation, partnership working, communications, marketing and digital, local implementation support) (Box 3). These had the potential to address multiple factors and take a systems approach. "Whole-system" also included working in ways that better integrate national and local functions to maximise impact, as led by PHE's nine regional teams.

Table 1 Domains of influences on mental health from four working groups (and number of factors)

\begin{tabular}{|c|c|c|c|c|}
\hline $\begin{array}{l}\text { Group } 1 \text { domains (and } \\
\text { the no. of factors) }\end{array}$ & $\begin{array}{l}\text { Group } 2 \text { domains (and } \\
\text { the no. of factors) }\end{array}$ & $\begin{array}{l}\text { Group } 3 \text { domains (and } \\
\text { the no. of factors) }\end{array}$ & $\begin{array}{l}\text { Group } 4 \text { domains (and } \\
\text { the no. of factors) }\end{array}$ & $\begin{array}{l}\text { Merged domains (and } \\
\text { the number of factors) }\end{array}$ \\
\hline $\begin{array}{l}\text { Individual } \\
\text { characteristics (5) }\end{array}$ & Individual (16) & & Individual resources (17) & Individual identity (12) \\
\hline $\begin{array}{l}\text { Identity and self- } \\
\text { perception (4) }\end{array}$ & & Personal identity (10) & & \\
\hline Health status (5) & Physical health (8) & & Physical health (11) & Physical health/ \\
\hline Behaviour (4) & Lifestyle (5) & $\begin{array}{l}\text { Behaviours (and } \\
\text { health) (13) }\end{array}$ & & behaviour (9) \\
\hline Environment (4) & Environment (13) & $\begin{array}{l}\text { Environment/ } \\
\text { community (7) }\end{array}$ & $\begin{array}{l}\text { Environmental-economic } \\
\text { (15) }\end{array}$ & Environment (7) \\
\hline Social determinants (5) & Economic (9) & $\begin{array}{l}\text { Education/work/ } \\
\text { financial (17) }\end{array}$ & Services (6) & Societal/economic (8) \\
\hline $\begin{array}{l}\text { Social and political } \\
\text { environment (11) }\end{array}$ & Global political (8) & & Societal-political (21) & \\
\hline Social capital (11) & Social (12) & $\begin{array}{l}\text { Social norms/culture } \\
\text { (9) }\end{array}$ & $\begin{array}{l}\text { Relationships and } \\
\text { community (16) }\end{array}$ & Social/community (17) \\
\hline $\begin{array}{l}\text { Life events and } \\
\text { transitions (3) }\end{array}$ & Life-long learning (5) & Connectedness (15) & Early life experiences (7) & \\
\hline $\begin{array}{l}\text { Total: } 9 \text { domains ( } 52 \\
\text { factors) }\end{array}$ & $\begin{array}{l}\text { Total: } 8 \text { domains ( } 76 \\
\text { factors) }\end{array}$ & $\begin{array}{l}\text { Total: } 6 \text { domains ( } 71 \\
\text { factors) }\end{array}$ & $\begin{array}{l}\text { Total: } 7 \text { domains (93 } \\
\text { factors) }\end{array}$ & $\begin{array}{l}\text { Total: } 5 \text { domains ( } 53 \\
\text { factors) }\end{array}$ \\
\hline
\end{tabular}




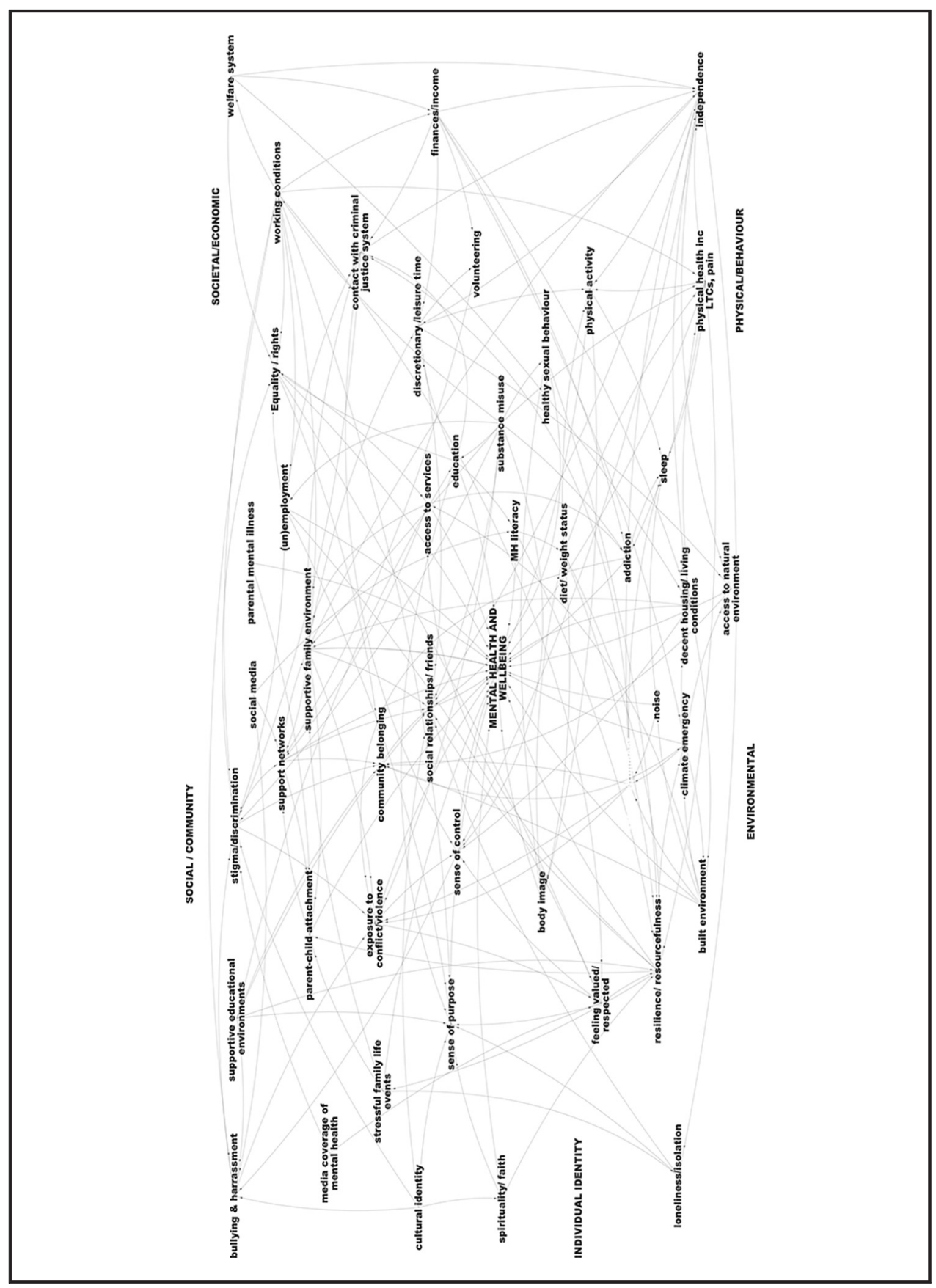




\section{Box 3. Where is more focus needed}

Factors influencing mental health where more action could be taken across multiple sectors

- Homelessness

- Welfare support

- Social cohesion

- Ethnicity

- Perinatal health

- Working conditions

- Stigma

- Discrimination

- Addiction

- Wider determinants generally

Common approaches for further action by PHE

- Influencing legislation

- Mental health in all policy

- Knowledge mobilisation

- Return on investment

- Improving data and evaluation

- Partnership working

- Communications

- Marketing and digital products

- Local implementation support

\section{Participant engagement}

Staff reported that their participation helped affirm their contribution to collective action on public mental health. The process reinforced the value of having a shared vision and strategic direction with clear communication between teams. Staff wanted a clear opportunity for the work to influence organisational strategy, alongside having leadership and senior endorsement of it.

" $\{. .$. ] a chance to meet with other colleagues in PHE and think about how my work fits with theirs"

Participants felt the interactive process was beneficial for networking between colleagues. The time together off-site was valued as "protected time" for collaborative and strategic thinking on mental health and learning about other teams' contributions. 
The learning-by-doing method helped to keep staff engaged during, between and after sessions. The production of a usable map and agreed next steps for collective action was welcomed. Access to technical expertise throughout the process was also valued and helped to stimulate interest in complex systems approaches to public health.

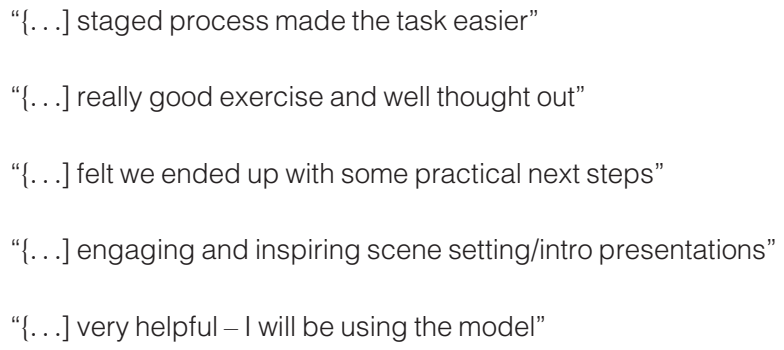

Comments on how to improve the process included having more background reading on systems mapping, having more teams present, being able to spend more time together and having better quality visual maps.

\section{Application and impact}

Three examples of staff application of learning were their work with localities on cooccurring mental health and substance misuse conditions; adverse childhood experiences; and a new strategic approach to reducing health inequalities. Participation helped staff to introduce and stimulate complex system thinking.

Shortly after this work, public mental health became a strategic priority for the organisation and the drafting of a five-year strategic framework was informed by the final map and complex systems approach and used in engagement with external partners and 250 stakeholders at a national meeting. Further work was also undertaken with staff to produce a series of logic models based on the factors in the map and the outputs and outcomes from the different programme teams across the organisation. This helped to develop a wholeorganisation approach to public mental health. The need for a whole-system (or complex systems) approach to public mental health was agreed as an underpinning principle for change within the draft framework. All the approaches identified in Box 3. have been turned into priorities for action e.g. mental health impact assessment work, knowledge mobilisation post, development of a data tool. The organisation-wide work has been on hold since the COVID-19 pandemic and pending organisation restructures, but the framework is being used to inform future direction and actions are underway.

The outputs have also been shared with researchers producing a conceptual framework for public mental health, as part of an National Institute for Health Research School for Public Health Research project. The work was intended to inform an organisation-wide initiative on complex system approaches, also on hold since the pandemic.

\section{Discussion}

The approach was effective in engaging a range of staff, forming a shared understanding between them and producing a complex systems map of the influences on population mental health and well-being, consistent with similar previous approaches (Cavill et al., 2020; Allender, et al., 2015). The work helped to convey the complexity of mental health and that a systems approach is needed to address it at the population level, requiring multiple teams to co-ordinate efforts. It instigated and led to further work to identify national programme priorities and the development of whole system approaches. 
There was high consistency amongst participants in understanding the range of influences on mental health and how these are linked, potentially reflecting staff familiarity with literature. The five domains of influences correspond to established models of the determinants of health (Dahlgren and Whitehead, 1991), literature on mental health determinants (Langellier, et al., 2019) (Lund, et al., 2018) and the four levels at which government policies to promote mental health and well-being can be directed, as identified in the Foresight report (Foresight Mental Capital and Well-being Project, 2008), namely, strengthening individuals, strengthening communities, reducing structural barriers to mental health and improving the quality of the physical environment. The fifth domain of physical health is included in Foresight's individual level alongside the structural level in terms of access to services. As stakeholders represented policy areas focussing on physical health it is perhaps unsurprising that this became a separate domain, combined with the current policy interest in the relationship between physical and mental health (Public Health England, 2018; Public Health England, 2019c; NHS England, 2019).

There is scope for further work to understand positive and negative associations and causal loops within the map, as has been undertaken elsewhere (Allender, et al., 2015; Langellier, et al., 2019). Several factors, often within the individual identity or community domain, were linked to multiple other factors and directly to mental health e.g. resilience/resourcefulness, sense of control, social connectedness, independence. These psychosocial factors are important mechanisms by which social determinants impact health outcomes (Foresight Mental Capital and Well-being Project, 2008; Stansfield and Bell, 2018). They are implicit to definitions of mental health, which may explain why participants did not identify explicit work against these factors in the workshop. In recent years, concepts of well-being (Foresight Mental Capital and Well-being Project, 2008) and the capabilities approach (Sen, 1985; Nussbaum, 2011) have helped to make explicit the importance of psychosocial factors and the interplay of internal and external factors in determining social outcomes.

These are important variables in many public mental health interventions and there is potential for joint work across teams on such factors that interact with different public health outcomes and policy areas. This can help break down siloed working and was fed back in the follow-up work. Applying a system thinking approach could facilitate joint working and support and strengthen the "lifecourse" focus adopted by PHE (Public Health England, 2019b) and a Health in All Policy approach (Public Health England, 2016).

The work also highlighted that many of the individual identity and community factors associated directly with mental health do not have good data. Better data on factors could also support the use of other complex approaches in public mental health such as system dynamic modelling which could provide a long-term view about the effectiveness of interacting systems. It is recognised elsewhere that the lack of data on causal mechanisms that drive mental health outcomes is a challenge for complex systems approaches to mental health (Langellier, et al., 2019; Wittenborn, et al., 2016).

The programme had some impact in building knowledge and skills in complex systems thinking and practice and identifying that further learning could have been beneficial. Carey et al. also note that capacity building in systems approaches is key to the success of applying systems thinking to practice (Carey et al., 2015). Having a valued method, with a national expert, along with an opportunity to learn something new, helped to encourage staff to allocate the time to participate. The steps outlined in the approach could be applied by others with experience in group facilitation. Whilst the Kumu software was a useful tool, like most mapping software, it is challenging to produce a map that is legible and easy to read whilst reflecting the complexity of the system.

The process was limited to internal stakeholders and further work could include mapping work with external partners and a wider literature review on determinants. This could help 
improve multi-sector collaboration, as well as generating a more comprehensive understanding of the conditions necessary for effective programmes and policies (Langellier et al., 2019). The engagement of local stakeholders and community members could produce wider insights and support ownership and adoption of effective communitycentred solutions to public mental health challenges (Allender et al., 2015; Stansfield et al., 2020).

\section{Conclusions}

"Great to have committed colleagues together in one room acting together on mental health" (Participant Feedback)

The process of stakeholder complex system mapping has been as useful as the product resulting from it. Complex system approaches are being used in many areas of public health and there is potential for it to support public mental health policy and practice. Given the centrality of mental health to other public health priorities, complex system thinking and approaches can contribute to achieving a whole-system response that addresses the mind-body-spirit relationship and the importance of socioeconomic-environmental determinants.

\section{Acknoledgments/Funding}

The project was partly funded by The Health Foundation.

\section{Note}

1. https://www.kumu.io/

\section{References}

Allender, S., Owen, B., Kuhlberg, J., Lowe, J. and Nagorcka-Smith, P., et al. (2015), "A community based systems diagam of obesity causes", PLoS One, Vol. 10 No. 7, pp. 1-12., doi: 10.1371/journal.pone.0129683.

Cabinet Office \& DHSC (2019), Advancing our health in the 2020s: Prevention Green Paper, London: HMG. Available at: www.gov.uk/government/consultations/advancing-our-health-prevention-in-the-2020s

Carey, G., Malbon, E., Carey, N., Joyce, A.and Crammond, B., et al. (2015), "Systems science and systems thinking for public health: a systematic review of the field", BMJ Open, Vol. 5 No. 12, pp. 1-9., doi: 10.1136/bmjopen-2015-009002.

Cavill, N., Richardson, D., Faghy, M., Bussell, C. and Rutter, H. (2020), "Using system mapping to help plan and implement city-wide action to promote physical activity", Journal of Public Health Research, Vol. 9 No. 3, pp. 278-284.doi: 10.4081/jphr.2020.1759.

Dahlgren, G. and Whitehead, M. (1991), "The main determinants of health model”, European Strategies for Tackling Social Inequities in Health: Levelling up Part 2, WHO Regional Office for Europe, Copenhagen.

Department of Health and Social Care (2011), No health without mental health: a cross government mental health outcomes strategy for people of all ages: HMG, London, available at: www.gov.uk/government/publications/no-health-without-mental-health-a-cross-government-outcomesstrategy

Foresight Mental Capital and Wellbeing Project (2008), Final Project report: The Government Office for Science, London, available at: www.gov.uk/government/collections/mental-capital-and-wellbeing

Foresight Obesity project (2007), Tackling obesities - future choices: Government Office for Science, London, available at: www.gov.uk/government/publications/reducing-obesity-future-choices

Hovmand, P. (2014), Community Based System Dynamics, Springer. New York, NY.

Langellier, B.A., Yang, Y., Purtle, J., Nelson, K.L. and Stankov, I., et al. (2019), "Complex systems approaches to understand drivers of mental health and inform mental health policy: a systematic review", 
Administration and Policy in Mental Health and Mental Health Services Research, Vol. 46 No. 2 , pp. 128-144, doi: 10.1007/s10488-018-0887-5.

Lund, C., Brooke Sumner, C., Baingana, F., Baron, E.C. and Breuer, E., et al. (2018), "Social determinants of mental disorders and the sustainable development goals: a systematic review of reviews", The Lancet Psychiatry, Vol. 5 No. 4, pp. 357-369, doi: 10.1016/S2215-0366 (18)30060-9.

McManus, J. (2017), "Complex public health challenges and local action: how does local government tackle complexity: webinar presentation", The Health Foundation, available at: www.slideshare.net/ jamesgmcmanus/complex-public-health-problems-systems-approaches

NHS England (2019), The NHS Long Term Plan: NHS, London, available at: www.longtermplan.nhs.uk/

Nussbaum, M. (2011), Creating Capabilities: The Human Development Approach, The Belknap Press of Harvard University Press. Cambridge, MA.

Patel, V., Saxena, S., Lund, C., Thornicroft, G. and Baingana, F., et al. (2018), "The lancet commission on global mental health and sustainable development”, The Lancet, Vol. 392 No. 10157, pp. 1553-1598, available at: https://doi.org/10.1016/S0140-6736(18)31612-X.

Peters, D. (2014), "The application of systems thinking in health: why use systems thinking", ? Health Research Policy and Systems, Vol. 12 No. 1, pp. 1-6, available at: www.health-policy-systems.com/ content/12/1/51.

Public Health England (2016), "Health in all policies: overview, Iondon: public health England", available at: www.gov.uk/government/publications/local-wellbeing-local-growth-adopting-health-in-all-policies

Public Health England (2016), Severe mental illness (SMI) and physical health inequalities: briefing: Public Health England, London, available at: www.gov.uk/government/publications/severe-mentalillness-smi-physical-health-inequalities/severe-mental-illness-and-physical-health-inequalities-briefing

Public Health England (2019a), A whole systems approach to obesity, Public Health England, London, available at: www.gov.uk/government/publications/whole-systems-approach-to-obesity

Public Health England, (2019b), Health matters blog: Prevention - A lifecourse approach: Public Health England, London, available at: www.gov.uk/government/publications/health-matters-life-course-appro ach-to-prevention/health-matters-prevention-a-life-course-approach

Public Health England (2019c), PHE Strategy 2020-2025: Public Health England, London, available at: www.gov.uk/government/publications/phe-strategy-2020-to-2025

Public Health England (2019d), "Universal approaches to improving children and young people's mental health and wellbeing", Report of the findings of a Special Interest Group, PHE. London, available at: www. gov.uk/government/publications/children-and-young-peoples-mental-health-prevention-evidence

Rutter, H., Savona, N. and Glonti, K. (2017), "The need for a complex systems model of evidence for public health", The Lancet, Vol. 390 No. 10112, pp. 2602-2604, available at: https://doi.org/10.1016/ S0140-6736(17)31267-9

Rutter, H., Cavill, N., Bauman, A. and Bull, F. (2019), "Systems approaches to global and national physical activity plans", Bulletin of the World Health Organization, Vol. 97 No. 2, pp. 162-165, available at: http://dx.doi.org/10.2471/BLT.18.220533

Sen, A. (1985), Commodities and Capabilities, Elsevier Science Pub. Co. Amsterdam. New York, NY.

Stansfield, J. and Bell, R. (2018), "Applying a psychosocial pathways model to improving mental health and reducing health inequalities: practical approaches", International Journal of Social Psychiatry, Vol. 65 No. 2, pp. 107-113, available at: https://doi.org/10.1177\%2F0020764018823816

Stansfield, J., South, J. and Mapplethorpe, T. (2020), "What are the elements of a whole system approach to community-centred public health? A qualitative study with public health leaders in england's local authority areas", BMJ Open, Vol. 10 No. 8, pp. 1-11, doi: 10.1136/bmjopen-2019-036044

The Health Foundation, (2018) Newsletter Feature: Mapping the influences on young people's mental health: The Health Foundation, London, available at: www.health.org.uk/newsletter-feature/mapping-theinfluences-on-young-peoples-mental-health

Vigo, D., Thornicroft, G. and Atun, R. (2016), "Estimating the true global burden of mental illness", The Lancet Psychiatry, Vol. 3 No. 2, pp. 171-178, available at: https://doi.org/10.1016/s2215-0366 (15)00505-2 
Wittenborn, A.K., Rahmandad, H., Rick, J. and Hosseinichimeh, N. (2016), "Depression as a systemic syndrome: mapping the feedback loops of major depressive disorder", Psychological Medicine, Vol. 46 No. 3, pp. 551-562, doi: 10.1017/S0033291715002044.

Wolpert, M. (2018), "Rethinking public mental health: learning from obesity", Lancet Psychiatry, Vol. 6 , available at: http://dx.doi.org/10.1016/S2215-0366(18)30046-4

\section{Corresponding author}

Jude Stansfield can be contacted at: jude.stansfield@phe.gov.uk

For instructions on how to order reprints of this article, please visit our website: www.emeraldgrouppublishing.com/licensing/reprints.htm

Or contact us for further details: permissions@emeraldinsight.com 